\title{
Editorial
}

\section{Magnus Ericsson}

Published online: 30 October 2011

(C) Springer-Verlag 2011

That there is an undoubted need, both in academia and business, for an international scientific journal, which combibnes traditional, well-researched academic papers and brief reports on topical issues with a lively debate on issues of concern to the mineral industries has been the driving force behind Raw Materials Report since its first issue in 1980. The journal has continued to be published in spite of that the fortunes of the mining industry has swung widely during these 30 years. With the present issue, the journal takes another decisive step forward and is relaunched as Mineral Economics-Raw Materials Report. Over the years, the journal has appeared under different names: Raw Materials Report, Journal of Mineral Policy, Business and Environment, Minerals \& Energy. The most recent changes signal a return to its roots: mining and minerals.

Springer Verlag will be the new publishers of Mineral Economics-Raw Materials Report. We are glad to have found such a professional and reputable home for the journal. As earlier, the Division of Economics at the Lulea University of Technology and the Raw Materials Group are standing behind the journal. The new Editor-in-Chief is Dr. Linda Wårell based in Luleå. Linda brings with her a solid background as a mineral economist and further new ideas of how the journal shall be revitalised and recapture its position as the leading scientific journal in its fields. We have a new Editorial Board to support her, which includes prominent industrialists, academics, and policymakers from government and international organizations from all over the world.

M. Ericsson $(\bowtie)$

Luleå University of Technology,

Luleå, Sweden

e-mail: magnus.ericsson@rmg.se
In spite of these changes, the focus of the journal remains the same as earlier: to provide a platform for multidisciplinarity, accessible, and policy-relevant academic research and to provide a bridge between traditional academic research and the global mineral industries.

We have decided to concentrate on minerals only as there are a number of well-establised publications which deal primarily with energy issues. We will cover coal, however. Our intention is to have the journal listed in the Thomson Reuters Science Citation Index as soon as possible in order for our authors to get full recognition of their work. We have already received full support from a number of internationally well-known researchers who have agreed to become members of our Editorial Board, and we have also received a series of highly interesting and relevant articles.

It is our intention to continue to widen the scope of the journal to cover all the issues of concern to the industry, to policy makers and to all other stakeholders. We will keep our international focus, to take a mediumor long-term view and to deal with the growing range of issues, which confront the industry worldwide. Issues of regulation, governance, and national economic development, as well as corporate strategies, sustainability, and the environment will be given equal prominence. The editors are keen to enter into a dialogue with the readers and authors and to discuss matters of concern and interest.

In brief, we expect the journal to continue to change and to grow with the increasing interest globally for natural resources and their role in economic and social development of countries and the world.

Magnus Ericsson

Founding Editor 